\title{
BMJ Open Quality Reducing late-onset neonatal sepsis in very low birthweight neonates with central lines in a low-and-middle- income country setting
}

\author{
Vinay Batthula, ${ }^{1}$ Sanjana H Somnath, ${ }^{1}$ Vikram Datta (D) ${ }^{1,2}$
}

To cite: Batthula V, Somnath SH, Datta V. Reducing late-onset neonatal sepsis in very low birthweight neonates with central lines in a low-andmiddle-income country setting. BMJ Open Quality 2021;10:e001353. doi:10.1136/ bmjoq-2021-001353

- Additional supplemental material is published online only. To view, please visit the journal online (http://dx.doi.org/10. 1136/bmjoq-2021-001353).

Received 23 January 2021 Accepted 2 May 2021

Check for updates

(C) Author(s) (or their employer(s)) 2021. Re-use permitted under CC BY-NC. No commercial re-use. See rights and permissions. Published by BMJ.

${ }^{1}$ Neonatology, Kalawati Saran Children's Hospital, New Delhi, India

${ }^{2}$ Neonatology, Lady Hardinge Medical College, New Delhi, India

Correspondence to Professor Vikram Datta; drvikramdatta@gmail.com

\section{ABSTRACT}

Background Late-onset neonatal sepsis (LONS) is a significant contributor to morbidity and mortality in very low birthweight (VLBW) neonates with indwelling central lines. Compliance to central line care bundles is suboptimal in low-and-middle-income country settings. Point of care quality improvement (POCQI) method may be used to improve the compliance gap. We used the POCQI method to achieve an improvement in compliance to central line care bundles with an aim to reduce LONS in a subset of VLBW neonates.

Methods A pre and post-intervention study consisting of three phases was conducted in a tertiary care neonatal intensive care unit. A root-cause analysis was undertaken to find the causes of LONS in VLBW babies with central lines. Multiple change ideas were identified and tested using sequential Plan-Do-Study-Act (PDSA) cycles to address the issue of reduced compliance to the central line care bundles. The change ideas tested in PDSA cycles which were successful were adopted. Compliance to the insertion and maintenance bundles was measured as process indicators. LONS, central line associated bloodstream infections and all-cause mortality rates were measured as outcome indicators.

Results A total of 10 PDSA cycles testing multiple change ideas (staff education, audio-visual aids, supply issues) were undertaken during the study duration. Bundles were not being used in the study setting prior to the initiation of the study. Insertion bundle compliance was above $90 \%$ and maintenance bundle compliance increased from $23.3 \%$ to $42.2 \%$ during the intervention and sustenance phases, respectively. A 43.3\% statistically significant reduction in LONS rates was achieved at the end of the study. No effect on mortality was seen.

Conclusion POCQI method can be used to improve compliance to central line care bundles which can lead to a reduction of LONS in VLBW neonates with central lines in situ.

\section{INTRODUCTION}

The impact of late-onset neonatal sepsis (LONS) on mortality and morbidity, including adverse neurodevelopmental outcomes and costs of healthcare in very low birthweight (VLBW) infants is well known. ${ }^{12}$ Increasing survival of premature and lower birth weight babies due to advances in perinatal care has led to a prolonged hospital stay and invasive procedures including central lines in this population of neonates making them vulnerable to LONS. $^{3-5}$ The suboptimal compliance to evidence-based measures in low and middle-income countries (LMICs) is known to be one of the causes for high infection rates in such settings. ${ }^{6-9}$ The central lineassociated bloodstream infection (CLABSI) bundle approach to central line care practices has been proven to be an evidence-based measure for reducing CLABSI/LONS rates in the neonatal intensive care unit (NICU)..$^{10} 11$ Quality improvement (QI) has improved the central line care practices and brought about a reduction in LONS and CLABSIs, thereby improving the quality of healthcare in NICUs of developed nations. ${ }^{12-16}$ Studies from LMIC settings, including India, are few and vary widely due to diverse contextual settings. ${ }^{17-21}$ The Point Of Care Quality Improvement (POCQI) methodology developed by WHO has been used in several maternal and neonatal health settings in LMIC settings. ${ }^{22-24}$ The current study was planned with an aim to reduce LONS incidence, CLABSI and allcause mortality among VLBW neonates with central lines in situ by improving compliance to central line insertion and maintenance bundles using the POCQI methodology.

\section{STUDY METHODOLOGY}

A prospective pre-post-intervention study was conducted from January 2018 to August 2019 in the Level III NICU of Lady Hardinge Medical College, New Delhi, India, a tertiary care teaching hospital. The hospital has an annual load of about 13000 deliveries and annual admissions of about 3000 babies in the NICU. The bed occupancy rate ranges from $80 \%$ to $125 \%$. VLBW neonates form about $6 \%$ of the total annual live births and $25 \%$ of the NICU admissions. The doctor:patient ratio in intensive care and high dependency 
units is 1:5, and the nurse:patient ratio is $1: 6$. In the stepdown unit, the doctor:patient ratio is 1:10 and nurse:patient ratio is $1: 15$. Sepsis and VLBW account for nearly half of all deaths in the unit. The study included all VLBW neonates with central lines for more than 48 hours during the NICU stay. The enrolled patients were followed until death or discharge. For the study, the following definitions were used. LONS was defined as the onset of sepsis's signs and symptoms after 72 hours of birth while CLABSI was diagnosed as per the Centre for Disease Control criteria. $^{25}$

The Centre for Disease Control CLABSI Bundle ${ }^{26}$ was adapted into a checklist for observing the proper line insertion and maintenance practices. Compliance to central line insertion and maintenance bundle checklists (online supplemental table 1) were used as process indicators in the study. Compliance was reported as a composite statistic, that is, if the staff did not perform even one component of the bundle, it was taken as noncompliant. Compliance scoring was done as the total number of central line procedures where all components of the insertion/maintenance bundles were performed correctly expressed as a percentage of the total number of procedures observed. The compliance scoring was noted and analysed during study phases II (intervention) and III (sustenance) only as the CLABSI bundle was not in routine use during study phase I (baseline). LONS rate calculated as number of LONS episodes per 1000 patientdays, CLABSI rate expressed as CLABSI episodes per
1000 central line days and mortality as mortality per 1000 patient-days were used as outcome indicators.

The study consisted of three predetermined phases (table 1), namely, phase I which consisted of baseline data collection (12 weeks); phase II, the intervention phase (24 weeks); and phase III, a sustenance phase (24 weeks). The duration of the study was planned as per operational convenience. The study used the POCQI method ${ }^{27}$ to improve the processes and outcomes of care in the identified study population.

Fish-bone analysis (figure 1) and process flow chart (figuresonline supplemental figure $1 \mathrm{a}, \mathrm{b}$ ) were used to conduct a root cause analysis of the possible causes for LONS and CLABSI in VLBW babies with central lines in our unit. It was observed that there was a lack of awareness among the NICU staff to the importance of the bundle approach and central line bundle components. Improving compliance to the CLABSI bundle required an increase in the awareness of central line care and bundle approach among the NICU staff. To achieve this, the team identified multiple change ideas which were tested using 10 PDSAs which are discussed in table 2.

\section{Sample size and statistical analysis}

For a power of $80 \%$ with alpha error of 0.05 and assuming a baseline LONS per 1000 patient-days of 5 and a postintervention reduction by $50 \%$ (2.5/1000 patient-days), the required sample size in each phase was 1000 patientdays.

Table 1 Table describing the three phases of the study

\begin{tabular}{|c|c|c|c|}
\hline Phase & Name of phase & $\begin{array}{l}\text { Duration } \\
\text { (weeks) }\end{array}$ & Interventions during the phase \\
\hline I & Baseline phase & 12 & $\begin{array}{l}\text { Routine procedures of catheter care and maintenance were } \\
\text { observed to gain understanding of the process flow } \\
\text { Baseline compliance to the central line insertion and maintenance } \\
\text { checklists (process indicators) was not obtained as there was no } \\
\text { routine policy of following central line insertion and maintenance } \\
\text { bundle prior to this study } \\
\text { Baseline incidence data were collected for the outcome } \\
\text { indicators }\end{array}$ \\
\hline II & Intervention phase & 24 & $\begin{array}{l}\text { A QI team was formed comprising resident doctors, nursing } \\
\text { supervisors, staff nurses, store in-charge nurse, multipurpose } \\
\text { workers and mothers of admitted babies } \\
\text { Process flow chart and fish bone diagram were used to conduct } \\
\text { a root cause analysis and identify factors contributing to LONS in } \\
\text { the VLBW babies with central lines in the unit } \\
\text { Multiple change ideas were developed and tested using short } \\
\text { sequential PDSA cycles to enable implementation of CLABSI } \\
\text { bundle } \\
\text { Education sessions for the staff regarding rational use of central } \\
\text { lines, proper insertion and maintenance techniques were } \\
\text { undertaken }\end{array}$ \\
\hline III & $\begin{array}{l}\text { Post-intervention/sustenance } \\
\text { phase }\end{array}$ & 24 & $\begin{array}{l}\text { Low compliance to maintenance bundle was addressed by } \\
\text { testing the idea of continuing education among staff and } \\
\text { knowledge testing with periodically conducted tests (PDSA 10) }\end{array}$ \\
\hline
\end{tabular}

CLABSI, central line associated bloodstream infection; LONS, late-onset neonatal sepsis; PDSA, Plan-Do-Study-Act; QI, quality improvement; VLBW, very low birth weight. 


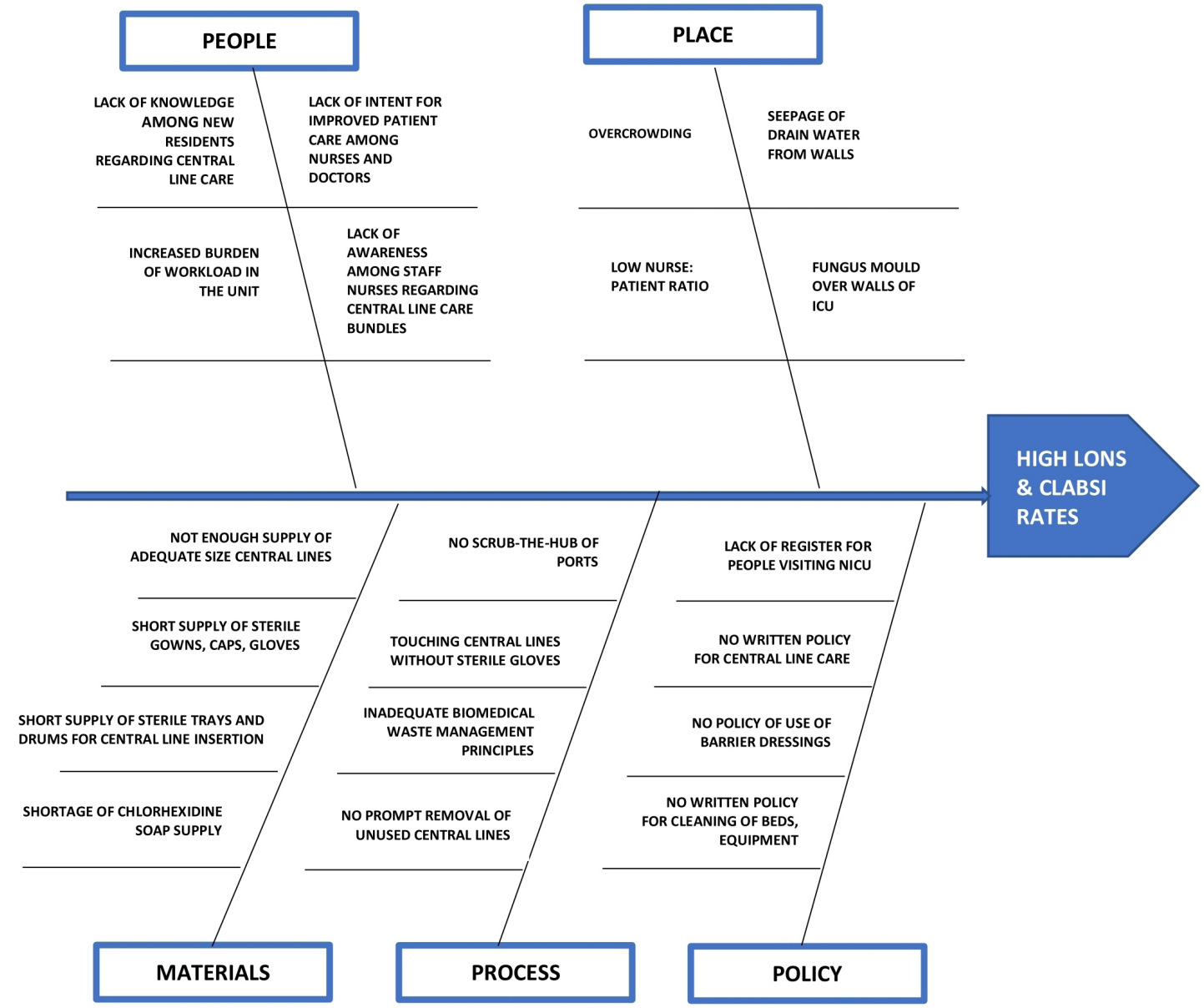

Figure 1 Fish bone analysis.

Data for the process and outcome indicators were collected monthly throughout the study period. Data thus generated were used to develop run charts and control charts (individual and moving range I-MR charts) depicting the different phases of the study. Direct observation and manual re-checking were used for assessing the completeness and accuracy of data.

Data were analysed using standard statistical tests (SPSS software V.20). Continuous variables were described as mean with SD and median with IQR. Parametric data were analysed using Student's t-test and analysis of variance test. Non-parametric data were analysed by the MannWhitney U test and Kruskal-Wallis test. Chi-square test or Fisher's exact test was used for categorical variables. Incidence rate ratios, $95 \% \mathrm{CI}$ and $\mathrm{p}$ value were determined for LONS, CLABSI and mortality rate outcomes. The level of significance was set as $p<0.05$, and all tests of significance were two-tailed.

Approval for the study was taken from the Institutional Ethics Committee. There was no conflict of interest for the authors in the study.

\section{Patient involvement}

As the enrolled patients were VLBW neonates, they were not involved in the research's design, conduct, reporting and dissemination plan. The study was related to improving processes of care concerning central line care in NICUs. The results of the study were disseminated through recurring experience sharing sessions among the facility staff.

\section{RESULTS}

Out of 774 VLBW babies admitted during the study period, 147 (18.9\%) with central lines for more than 48 hours were enrolled. A total of 33 babies in phase I (1002 patient-days) were analysed for outcome indicators; 63 babies in phase II (1834 patient-days) and 51 in phase III (1874 patient-days) were observed for both process and outcome indicators. The baseline characteristics of the enrolled neonates are shown in online supplemental table 2. Babies with Apgar score $>7$, the median duration of the central line in days, median length of hospital stay and survival of extremely low birthweight (ELBW) babies were significantly more in the third phase of the study. The other variables were not significantly different across the three phases.

\section{Process indicators}

A total of 15 out of $63(23.8 \%)$ central line insertion procedures were observed during phase II. Compliance to the insertion bundles was seen in 14 out of the 15 


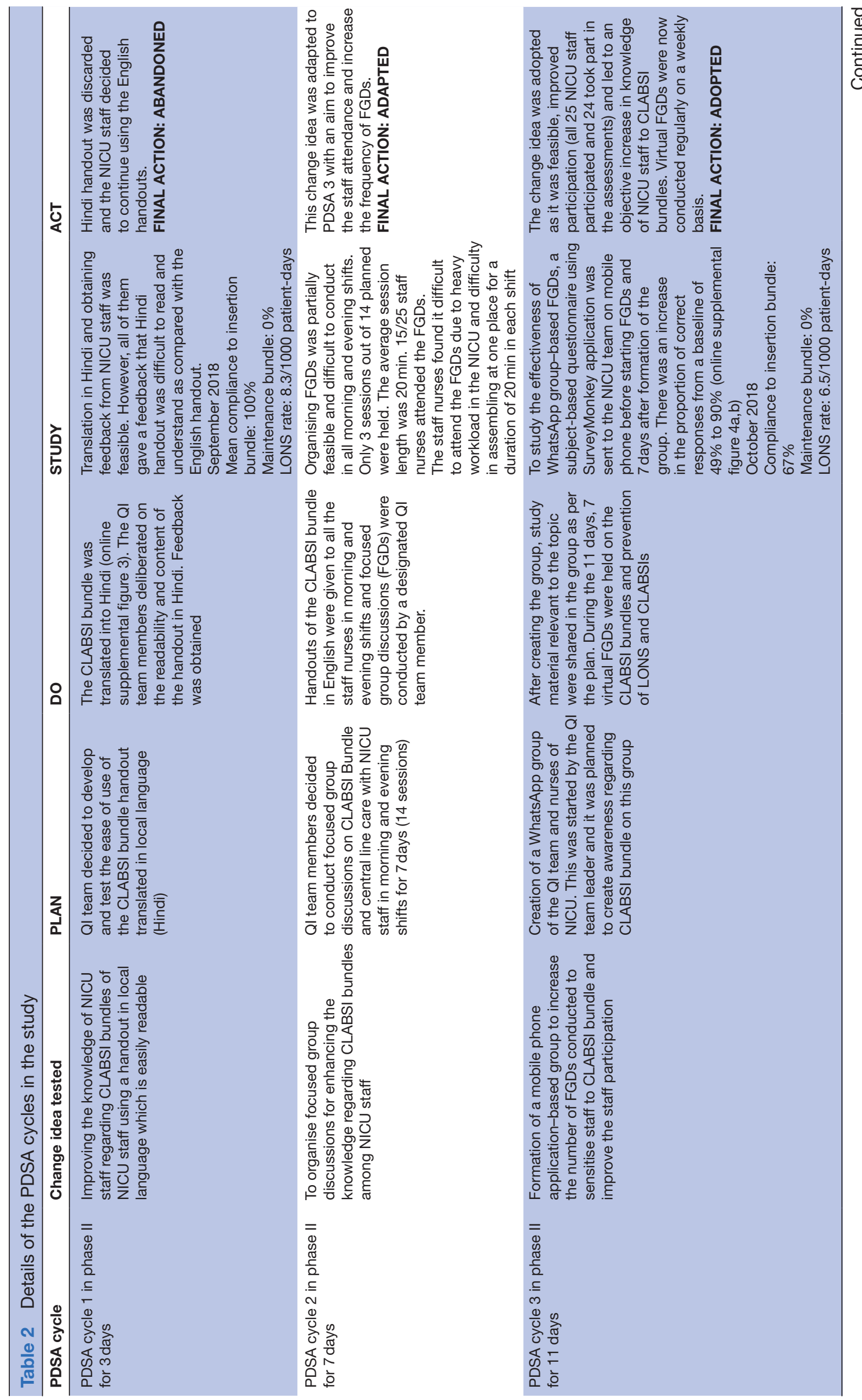




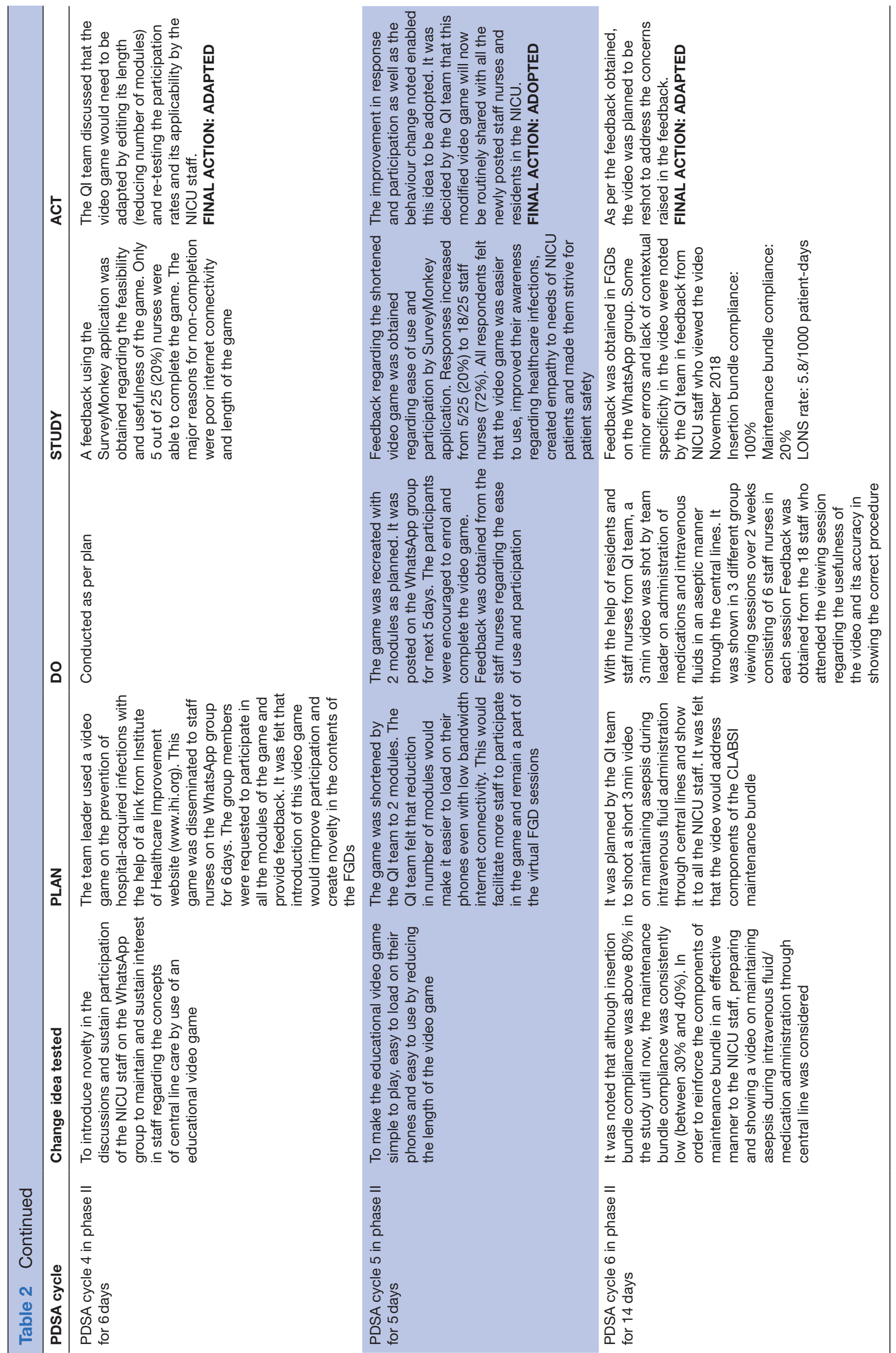

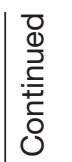




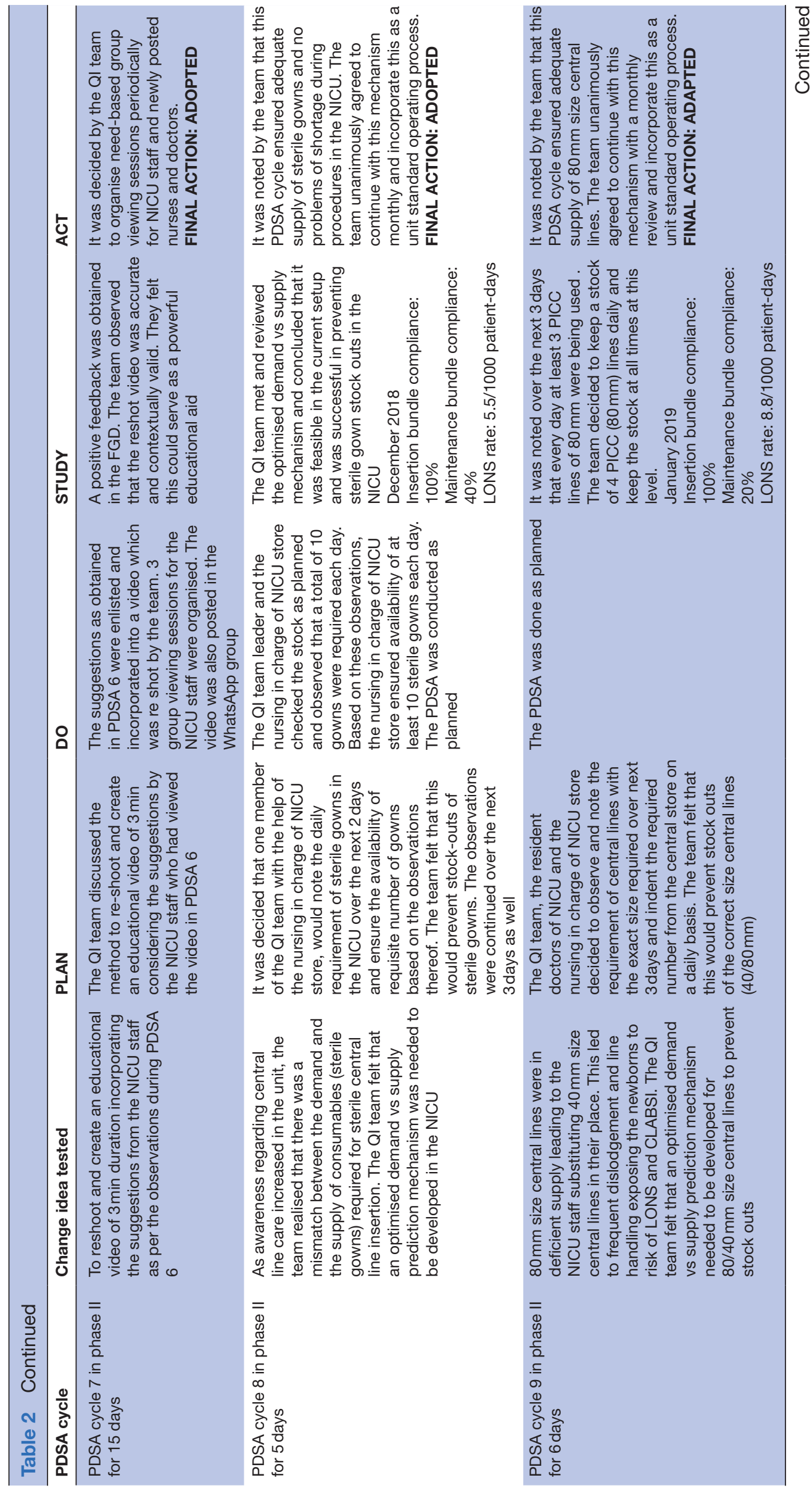




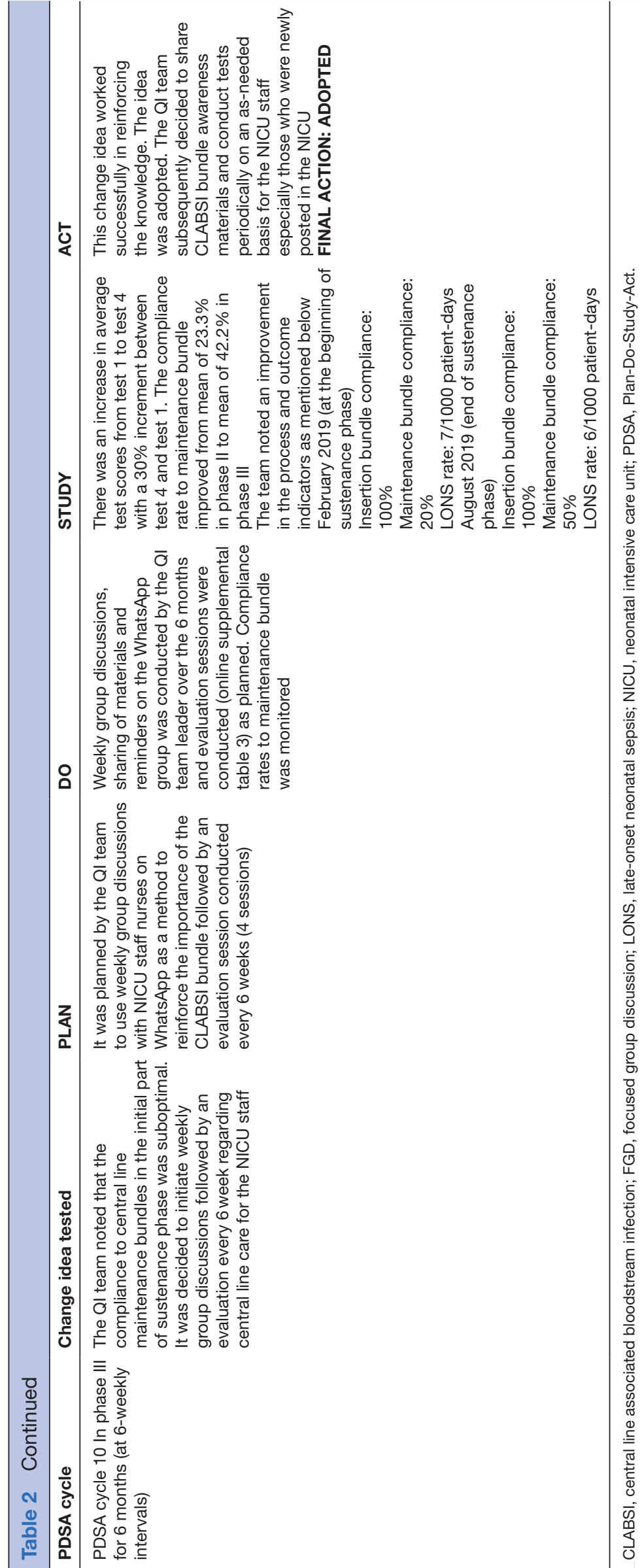




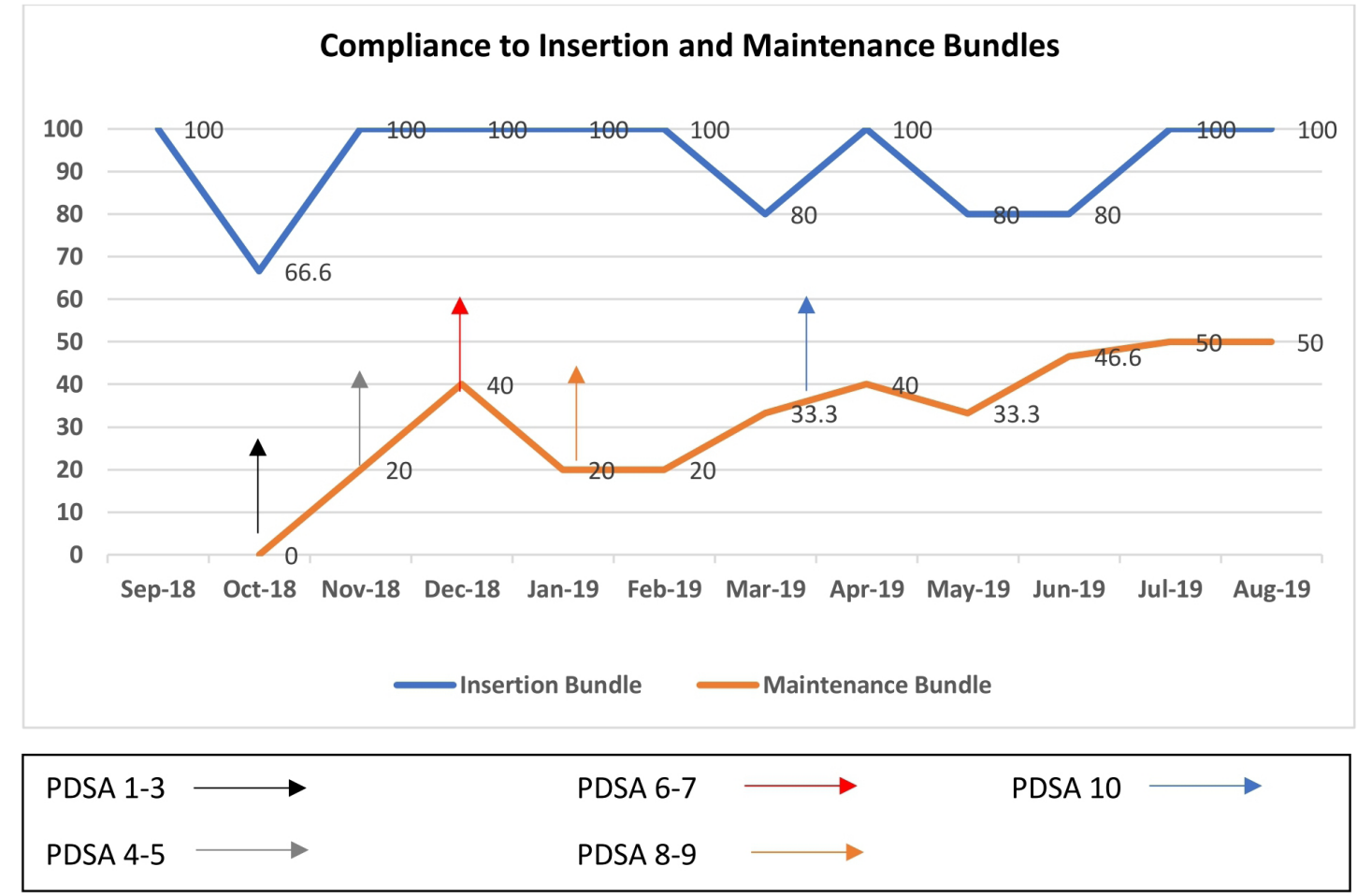

Figure 2 Compliance to insertion and maintenance bundles over the study duration.

(93.3\%) observations. In phase III, 30 out of $51(58.8 \%)$ insertions were observed. Compliance to insertion bundle was present in 27 of the 30 observations (90\%) (figure 2).

A total of 30 observations were undertaken for the maintenance bundle check in phase II. The compliance with the central line maintenance bundle in phase II was seen in 7 out of 30 observations (23.3\%). In phase III, 90 observations were undertaken over 6 months out of which compliance was noted in 38 (42.2\%) observations. As compared with phase II, this rise was statistically not significant $(\mathrm{p}=0.06)$.

The compliance with the maintenance bundle's components during phase II was calculated using 30 observations over the 63 central lines inserted (450 central line days) during this period. The compliance to hand hygiene and aseptic dressing for the central lines was the highest among the maintenance bundle components (85\% compliance), and the scrubbing of the hub was the least performed in the bundle ( $70 \%$ compliance). The compliance to replacement of the dressing when dislodged was $80 \%$ and compliance to prompt removal of the line when not in use was $75 \%$ (prompt removal defined as the removal of line within 24 hours of having no further indication or baby on enteral feeds $120 \mathrm{~mL} /$ $\mathrm{kg}$ /day). Changing intravenous infusion sets were done in the unit as per protocol before starting the study; hence, compliance with this component was not studied separately.

\section{Outcome indicators}

The mean LONS rate (figure 3) showed a reduction from 12 in phase I to 6.95 per 1000 patient-days in phase
II $(42 \%$ reduction, $\mathrm{p}=0.0002)$. In phase III, a further reduction to 6.8 per 1000 patient-days $(43.3 \%$ reduction, $\mathrm{p}=0.00016$ ) was achieved compared with phase I.

There was a decline in the mean CLABSI rate per 1000 central line days from 16.04 in phase I to 8.8 in phase II $(45 \%$ reduction, $\mathrm{p}=0.676)$ which subsequently rose to 10.2 in phase III of the study ( $36.4 \%$ reduction, $\mathrm{p}=0.8$ ) as compared with phase I. The mean mortality rate per 1000 patient-days was 7.4 in phase I, which slightly reduced to 6.25 in phase II ( $15.5 \%$ reduction, $\mathrm{p}=0.33$ ) and rose to 8.3 in phase III. A $12 \%$ increase was observed in phase III ( $\mathrm{p}=0.8$ ) compared with phase I (table 3). I-MR control charts used to analyse the data collected on the outcome indicators (online supplemental figure 2) show a specialcause variation for LONS reduction in the intervention and sustenance phases (tables 3 and 4, figure 3 ).

It was observed that the incidence of LONS in phase II was 0.58 times that of phase I. The risk of developing LONS was 1.7 times in phase I compared with phase II, which was statistically significant. The CLABSI and allcause mortality rate did not show a significant reduction (table 4).

\section{DISCUSSION}

The current study was conducted to reduce LONS in a tertiary care teaching hospital NICU using POCQI method to improve central line care bundles' compliance. The study led to a $42 \%$ reduction in LONS rates from baseline but no significant reduction in the CLABSI or mortality rates in the study subjects in a VLBW population with central lines in situ. 


\section{Late Onset Sepsis Rates}

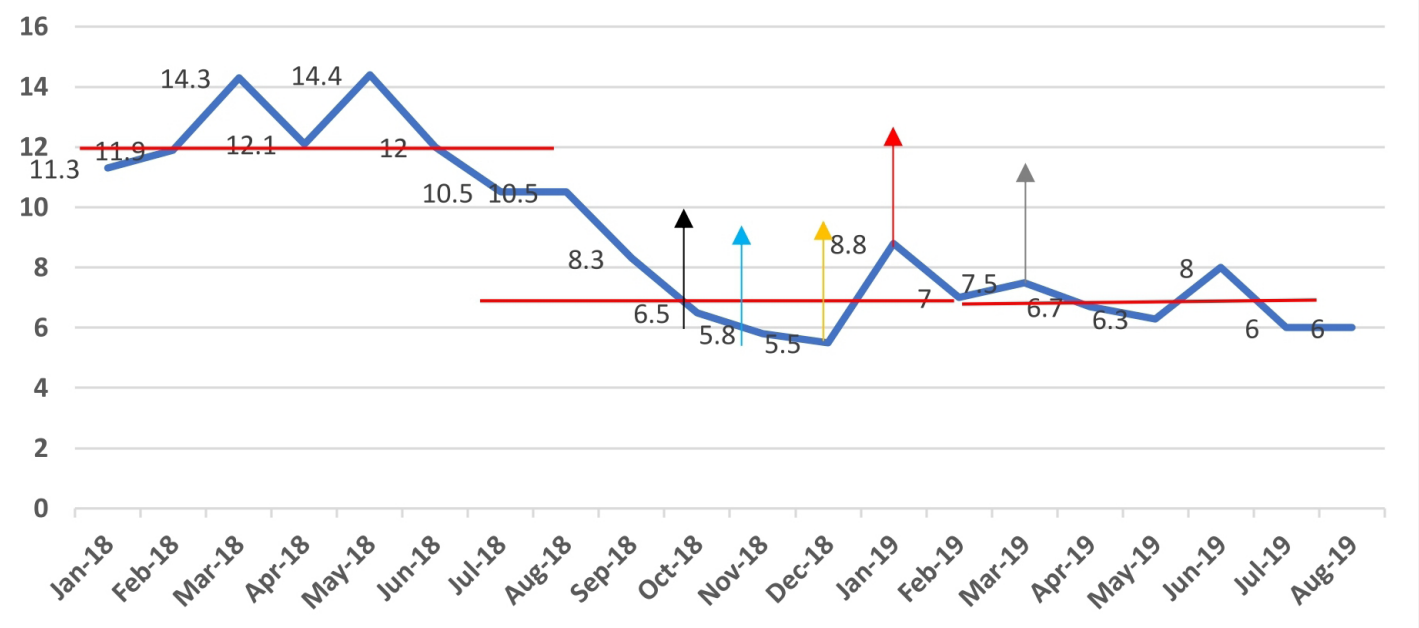

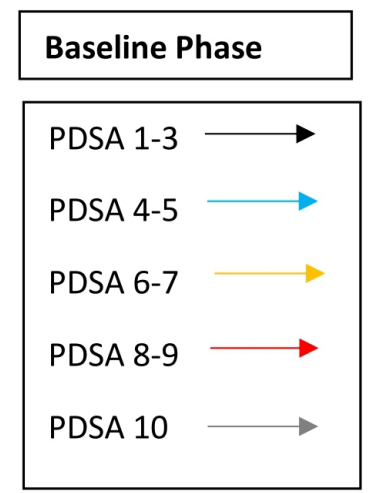

\section{\begin{tabular}{ll} 
Intervention Phase $\quad$ Sustenance Phase \\
\hline
\end{tabular}}

Median

Figure 3 Late-onset sepsis rates over the study duration.

Compliance to the Central Line Care bundles can be linked to multiple root causes as shown in figure 1 . The key factors among them being issues related to processes of care, materials and people-related causes. The QI team used the POCQI method to test a series of change ideas focusing on the root causes as mentioned previously. PDSA cycle 1 was conducted to develop and test the ease of use of the CLABSI bundle handout translated in local language (Hindi) from the existing English version. Feedback was obtained from the NICU staff that Hindi handout was difficult to read and understand as compared with the English. Hence, the team continued to use the English handouts. PDSA cycle 2 was done to test the feasibility of focused group discussions for knowledge enhancement of the NICU staff. It was observed that it was difficult to conduct such sessions every day. Hence, this change idea was adapted to PDSA 3. PDSA cycle 3 consisted of creation of a mobile phone application-based group to increase

Table 3 Outcome indicators in the different phases of the study

\begin{tabular}{llll}
\hline & Phase I & Phase II & Phase III \\
\hline Total central line insertions observed & 33 & 63 & 51 \\
\hline Total central line days & 187 & 450 & 392 \\
\hline Total no of patient-days & 1002 & 1834 & 1874 \\
\hline LONS/1000 patient-days & 12 & 6.95 & 6.8 \\
\hline Total CLABSI episodes & 3 & 4 & 4 \\
\hline CLABSI rate/1000 central line days & 16.04 & 8.8 & 10.2 \\
\hline \% of LONS accounted by CLABSI & $25 \%$ & $31 \%$ & $31 \%$ \\
\hline CLABSI/1000 patient-days & 2.99 & 2.17 & 2.13 \\
\hline Mortality rate/1000 patient-days & 7.4 & 6.25 & 8.3 \\
\hline
\end{tabular}

CLABSI, central line associated bloodstream infection; LONS, late-onset neonatal sepsis. 


\begin{tabular}{lllll}
\multicolumn{2}{l}{ Table 4} & Incidence rate ratios of outcome indicators in the study & & \\
\hline Outcome & Phases & P value & Incidence rate ratio & $\mathbf{9 5 \%}$ Cls \\
\hline LONS & Phase II vs phase I & $\mathbf{0 . 0 0 0 2}$ & $\mathbf{0 . 5 8 1}$ & $\mathbf{0 . 4 2 9}$ to $\mathbf{0 . 7 8 0}$ \\
LONS & Phase III vs phase I & $\mathbf{0 . 0 0 0 1 6}$ & $\mathbf{0 . 5 6 4}$ & $\mathbf{0 . 4 1 1}$ to $\mathbf{0 . 7 6 8}$ \\
CLABSI & Phase II vs phase I & 0.676 & 0.55 & 0.093 to 3.782 \\
CLABSI & Phase III vs phase I & 0.8 & 0.636 & 0.107 to 4.342 \\
Mortality rate & Phase II vs phase I & 0.33 & 0.84 & 0.596 to 1.177 \\
Mortality rate & Phase III vs phase I & 0.8 & 1.117 & 0.809 to 1.539
\end{tabular}

CLABSI, central line associated bloodstream infection; LONS, late-onset neonatal sepsis.

the number of focused group discussions. A subjectbased questionnaire was used to study the effectiveness of this change. There was an increase in the proportion of correct responses from a baseline of $49 \%$ to $90 \%$. The change idea was adopted as it was feasible, improved the staff participation and led to an increase in knowledge of NICU staff to CLABSI bundles. Wang et al from China used education, feedback and group discussions to implement the bundle and checklist. ${ }^{28}$ In PDSA cycles 4 and 5 , the QI team created and edited an educational video game consisting of five modules on prevention of hospitalacquired infections. This led to an improvement in participation as well as the behaviour change in the NICU staff. In PDSA cycles 6 and 7, a 3 min video on maintaining asepsis during intravenous fluid administration through central lines was created and subsequently edited by the team. We observed that the audio-visual content developed and tested in PDSA cycles 4-7 enhanced participation and interest in the NICU teams and also led to an increase in their awareness regarding care of central lines. Sinha et al used an educational video similar to our study to educate the NICU staff regarding the sterile fluid administration method. ${ }^{29}$ Frequent stockouts of essential supplies interfere with routine processes of care and lead to non-adherence to standard guidelines, for example, CLABSI Bundles. In PDSA cycles 8 and 9, we tested and adopted an optimised demand versus supply prediction mechanism to prevent stockout of sterile gowns and size $80 / 40 \mathrm{~mm}$ central lines in the NICU.

Most of the contemporary studies have observed that ensuring compliance to maintenance bundles is the difficult part in the implementation phase. ${ }^{14} 152030-32$ Improving the central line care bundle compliance is a resource-intense activity and requires intensive monitoring and mentoring for prolonged periods. The challenges of resources being paramount in LMIC settings become the major bottleneck in implementing the said bundle approach more so during sustenance phases .

We conducted a PDSA cycle during phase III of the study as the compliance to central line maintenance bundles in this phase was found to be suboptimal. We initiated weekly group discussions followed by an evaluation regarding central line care for the NICU staff. As a result of this change, we noted an increase in the compliance to maintenance bundle from a mean of
$23.3 \%$ in phase II to mean of $42.2 \%$ in phase III. Intensive monitoring is required to observe central line insertions and ensure sustained compliance to the central line bundles. ${ }^{19-21} 283334$

Compliance to maintenance bundle is an essential factor in reducing LONS rates in NICU as observed by Kaplan et al. ${ }^{14}$ NICUs having greater than $90 \%$ compliance to maintenance bundle showed nearly $50 \%$ reduction in sepsis as compared with those with compliance less than $90 \% .^{14}$ Compliance to maintenance bundles ranged from $65 \%$ to $90 \%$ in several studies. ${ }^{15} 30-34$ The compliance to maintenance bundles in an Indian study was lower $(60 \%-69 \%)$ as compared with Western studies and showed a decrease in the sustenance phase. ${ }^{20}$ Interventions in LMIC settings should focus on concurrent improvements directed towards health systems, policies and infrastructure rather than implementing checklists in isolation. ${ }^{35}$

The change ideas tested and implemented by our team using the PDSA approach led to an improvement in the knowledge of NICU staff which translated into increased compliance to insertion and maintenance bundle. Enhanced compliance to the bundles led to an improvement in the outcome indicators of LONS and CLABSI. The reduction in LONS achieved by our intervention was slightly lower than other studies wherein reduction rates for LONS ranged from $44 \%$ to $75.6 \%$ in a subset of VLBW neonates. ${ }^{15} 162936$ A lower rate of reduction seen in our study could have been due to lack of a system-wide implementation at a single setting incorporating minimal interventions over a limited study period.

Contextual factors can significantly affect the study outcomes, as noted by other authors. ${ }^{737}$ In our study, presence of factors, for example, an unfavourable nurse, doctor:patient ratio, frequent staff rotation, humid and warm weather favouring microbial proliferation, a higher rate of admissions of extremely low birthweight neonates, survival in phase III and overcrowding may have had affected the effect size unfavourably.

There was a decline in mean CLABSI rates across phase I, II by $45 \%$, and III a $36.4 \%$ reduction compared with phase I. These reductions were not statistically significant. The possible reasons for a slower decline in the CLABSI rates in our study population are complex to understand. We tried to reduce CLABSI using the same 
approach to minimise LONS, that is, by trying to improve the compliance to the adapted version of the central line care bundles. The compliance to maintenance bundle in our research was suboptimal and could have contributed to a lower reduction in CLABSI rates. The bundles used in various studies for CLABSI prevention are difficult to compare with our study due to a difference in method and techniques. ${ }^{15} 1618193738$ Studies from China, India and Pakistan have reported a much higher reduction in CLABSI rates than our study. A study conducted on 110 VLBW neonates in China ${ }^{28}$ by Wang et al, using central line bundle guidelines and a standard checklist, achieved a significant reduction in central line infections from 10 to 2.2 infections/1000 catheter days. In another study from India which included 1565 term and late preterm neonates, an $89 \%$ reduction in CLABSI and $41 \%$ reduction in mortality (both statistically significant) was demonstrated..$^{20}$ Using evidence-based interventions, CLABSI prevention package and nurse empowerment, a tertiary care NICU in Pakistan reduced CLABSI rates across all admitted neonates regardless of gestational age by $70 \%{ }^{21}$ This study intervention was conducted in a resourcereplete setting of Aga Khan University with a very favourable nurse:patient ratio and NICU staffing pattern. None of these studies has evaluated the reduction in CLABSI rates in VLBW neonates as has been done in our study. This per se can explain the lower reductions in CLABSI observed by us. It is reported that reducing CLABSI in VLBW and ELBW neonates are very challenging. ${ }^{37}$ In a meta-analysis by Payne et al in 2017 on the use of care bundles to reduce CLABSI in neonatal units, a subgroup analysis on VLBW neonates was conducted, revealing an insignificant reduction in CLABSI rate, a finding in conformity with our observations. ${ }^{39}$ In addition, it brings forth the importance of a skilled workforce, an essential prerequisite for any successful quality improvement initiative, the need for larger sample size, more interventions and more stringent diagnostic facilities that are often not available in LMIC settings.

Our study did not show any effect on mortality indicators of the study population. Some studies using QI methods for improving compliance to CLABSI bundle have shown mixed results, showing no significant reduction in mortality ${ }^{213640}$ in contrast to others ${ }^{18} 20$ who have showed a substantial reduction in mortality rates. Mortality in VLBW neonates could be due to multiple causes like extreme prematurity, asphyxia, severe RDS, IVH, BPD, PPHN and pulmonary haemorrhage. ${ }^{41}$ To demonstrate the effect of a single intervention on reduction of mortality in a VLBW subset would require a much larger sample size. This can be achieved through a QI collaborative study design with an extended sustenance phase.

There were a few strengths of the study. Our study was done in a LMIC setting in an exclusive cohort of VLBW babies with central lines in situ. The study applied the POCQI methodology to address the problem of LONS among such VLBW neonates by implementing and improving compliance to central line care bundles. The study reports data on compliance with central line care bundles, including compliance with individual components and reports on a sustenance period of 6 months.

Our study had a few limitations. The study was undertaken in a single setting with a limited sample size over a fixed period. A collaborative study design would have yielded a more significant impact and understanding on the effectiveness of POCQI in reducing LONS and CLABSI in VLBW neonates in LMIC settings and is increasingly being regarded as the need of the hour in such settings. ${ }^{42}$ A single investigator did the measurements of compliance and data recording. However, this limitation was turned to an advantage as it led to a lack of inter-observer variability and ensured high-quality data capture. Hence, only a limited number of central line insertions and maintenance checklists could be checked for compliance with potential observation bias in the study. There was a periodic rotation of resident doctors and an influx of new nurses who were yet to be trained, which caused periodic fluctuations in the study's asepsis protocols. The organisation of induction sessions addressed this as a standard unit policy. We could not study the impact of the bundle elements' components on the outcomes, cost-effectiveness of implementing checklists, balancing measures, and long-term impact on growth and neurodevelopment.

The study has good generalisability for similar settings as the POCQI methodology has proven to be a useful tool to achieve improvements in processes and outcomes of care in resource-constrained settings. ${ }^{22} 23$ POCQI can seed regional QI collaboratives across LMIC settings using QI to improve compliance to evidence-based bundles, thus catalysing better infection control in busy NICUs. ${ }^{15} 16333438$ Studying more extended sustenance periods, cost-benefit analysis of implementing checklists and the impact of individual interventions of bundles could be included in future study designs. Each NICU could form its bundle by selecting the best interventions from such studies relevant to their context for better infection control practices in the units. ${ }^{434}$ The newer changes in healthcare guidelines and evidence-based interventions could be included as part of the nursing curriculum. ${ }^{45}$

To conclude, the POCQI method is a useful and simple tool to improve healthcare personnel's compliance with evidence-based guidelines in resource-limited settings. It can aid in reduction of NICU infection rates and could be scaled up across similar settings after contextual adaptations.

Contributors VB was involved in the design, data collection, analysis and led the QI team responsible for the implementation of the change ideas. SHS was part of the QI team, was involved in implementation, performed data analysis, interpretation and helped in the drafting of the manuscript. VD designed and conceptualised the study, was part of the QI team, performed data analysis, critically reviewed the manuscript and approved the final manuscript. All authors reviewed and approved the final submission.

Funding The authors have not declared a specific grant for this research from any funding agency in the public, commercial or not-for-profit sectors. Publication of 
this article is made Open Access with funding from the Nationwide Quality of Care Network.

Competing interests None declared.

Patient consent for publication Not required.

Ethics approval Approved by the Ethical Committee for Human Research, Lady Hardinge Medical College, New Delhi, India.

Provenance and peer review Not commissioned; externally peer reviewed.

Data availability statement Data are available on reasonable request. All data relevant to the study are included in the article or uploaded as online supplemental information.

Supplemental material This content has been supplied by the author(s). It has not been vetted by BMJ Publishing Group Limited (BMJ) and may not have been peer-reviewed. Any opinions or recommendations discussed are solely those of the author(s) and are not endorsed by BMJ. BMJ disclaims all liability and responsibility arising from any reliance placed on the content. Where the content includes any translated material, BMJ does not warrant the accuracy and reliability of the translations (including but not limited to local regulations, clinical guidelines, terminology, drug names and drug dosages), and is not responsible for any error and/or omissions arising from translation and adaptation or otherwise.

Open access This is an open access article distributed in accordance with the Creative Commons Attribution Non Commercial (CC BY-NC 4.0) license, which permits others to distribute, remix, adapt, build upon this work non-commercially, and license their derivative works on different terms, provided the original work is properly cited, appropriate credit is given, any changes made indicated, and the use is non-commercial. See: http://creativecommons.org/licenses/by-nc/4.0/.

ORCID iD

Vikram Datta http://orcid.org/0000-0002-1047-6884

\section{REFERENCES}

1 Stoll BJ, Hansen N, Fanaroff AA, et al. Late-onset sepsis in very low birth weight neonates: the experience of the NICHD Neonatal Research Network. Pediatrics 2002;110:285-91.

2 Stoll BJ, Hansen NI, Adams-Chapman I, et al. National Institute of Child Health and Human Development Neonatal Research Network. Neurodevelopmental and growth impairment among extremely lowbirth-weight infants with neonatal infection. Jama 2004;292:2357-65.

3 Dong Y, Speer CP. Late-onset neonatal sepsis: recent developments. Arch Dis Child Fetal Neonatal Ed 2015;100:F257-63.

4 Boghossian NS, Page GP, Bell EF, et al. Late-onset sepsis in very low birth weight infants from singleton and multiple-gestation births. $J$ Pediatr 2013;162:1120-4.

5 Zea-Vera A, Ochoa TJ. Challenges in the diagnosis and management of neonatal sepsis. J Trop Pediatr 2015;61:1-3.

6 World Bank Country and Lending Groups - World Bank Data Help Desk. Available: https://datahelpdesk.worldbank.org/ knowledgebase/articles/906519-world-bank-country-and-lendinggroups [Accessed 12 Nov 2020].

7 Lee YSH, Stone PW, Pogorzelska-Maziarz M, et al. Differences in work environment for staff as an explanation for variation in central line bundle compliance in intensive care units. Health Care Manage Rev 2018;43:138-47.

8 Pakenham-Walsh N, Bukachi F. Information needs of health care workers in developing countries: a literature review with a focus on Africa. Hum Resour Health 2009;7:30.

9 Kruk ME, Pate M, Mullan Z. Introducing the Lancet Global Health Commission on high-quality health systems in the SDG era. Lancet Glob Health 2017;5:e480-1.

10 . How-to guide: prevent central line-associated bloodstream infections. Cambridge, MA Institute for Healthcare Improvement; 2012. www.ihi.org [Accessed 2 Oct 2020].

11 Powers RJ, Wirtschafter DW. Decreasing central line associated bloodstream infection in neonatal intensive care. Clin Perinatol 2010;37:247-72.

12 Lachman P, Jayadev A, Rahi M. The case for quality improvement in the neonatal intensive care unit. Early Hum Dev 2014;90:719-23.

13 El-Atawi K, Elhalik M, Dash S. Quality improvement initiatives in neonatal intensive care unit (NICU) for improved care outcomes - a review of evidence. J Pediatr Neonatal Care 2019;9.

14 Kaplan HC, Lannon C, Walsh MC, et al. Ohio Perinatal Quality Collaborative. Ohio statewide quality-improvement collaborative to reduce late-onset sepsis in preterm infants. Pediatrics 2011;127:427-35.

15 Horbar JD, Rogowski J, Plsek PE, et al. Collaborative quality improvement for neonatal intensive care. NIC/Q Project Investigators of the Vermont Oxford Network. Pediatrics 2001;107:14-22.

16 Bizzarro MJ, Sabo B, Noonan M, et al. Central Venous Catheter Initiative Committee. A quality improvement initiative to reduce central line-associated bloodstream infections in a neonatal intensive care unit. Infection Control \& Hospital Epidemiology 2010;31:241-8.

17 Rowe AK, Rowe SY, Peters DH, et al. Effectiveness of strategies to improve health-care provider practices in low-income and middle-income countries: a systematic review. Lancet Glob Health 2018;6:e1163-75.

18 Rosenthal VD, Dueñas L, Sobreyra-Oropeza M, et al. Findings of the International Nosocomial Infection Control Consortium (INICC), part III: effectiveness of a multidimensional infection control approach to reduce central line-associated bloodstream infections in the neonata intensive care units of 4 developing countries. Infect Control Hosp Epidemiol 2013a;34:229-37.

19 Zhou Q, Lee SK, Hu X-jing, et al. Successful reduction in central lineassociated bloodstream infections in a Chinese neonatal intensive care unit. Am J Infect Control 2015;43:275-9.

20 Balla KC, Rao SP, Arul C, et al. Decreasing central line-associated bloodstream infections through quality improvement initiative. Indian Pediatr 2018;55:753-6.

21 Hussain AS, Ahmed AM, Arbab S, et al. CLABSI reduction using evidence based interventions and nurse empowerment: a quality improvement initiative from a tertiary care NICU in Pakistan. Arch Dis Child 2021;106:archdischild-2019-318779.

22 Datta V, Saili A, Goel S, et al. Reducing hypothermia in newborns admitted to a neonatal care unit in a large academic hospital in New Delhi, India. BMJ Open Qual 2017;6:e000183.

23 Srivastava S, Datta V, Garde R, et al. Development of a hub and spoke model for quality improvement in rural and urban healthcare settings in India: a pilot study. BMJ Open Qual 2020;9:e000908.

24 Mehta P, Srivastava S, Aggrohiya D, et al. Quality improvement initiative to improve the screening rate of retinopathy of prematurity in outborn neonatal intensive care graduates. Indian Pediatr 2018;55:780-3.

25 Centers for Disease Control and Prevention. CDC/NHSN surveillance definitions for specific types of infections; 2017.

26 Marschall J, Mermel LA, Fakih M, et al. Strategies to prevent central line-associated bloodstream infections in acute care hospitals: 2014 update. Infect Control Hosp Epidemiol 2014;35:753-71.

27 World Health Organization. Improving the quality of hospital care for mothers and newborns: coaching manual; 2020

28 Wang W, Zhao C, Ji Q, et al. Prevention of peripherally inserted central line-associated blood stream infections in very low-birthweight infants by using a central line bundle guideline with a standard checklist: a case control study. BMC Pediatr 2015;15:69.

29 Sinha AK, Murthy V, Nath P, et al. Prevention of late onset sepsis and central-line associated blood stream infection in preterm infants. Pediatr Infect Dis J 2016;35:401-6.

30 Bannatyne M, Smith J, Panda M, et al. Retrospective cohort analysis of central line associated blood stream infection following introduction of a central line bundle in a neonatal intensive care unit. Int J Pediatr 2018;2018:4658181.

31 Fisher D, Cochran KM, Provost LP, et al. Reducing central lineassociated bloodstream infections in North Carolina NICUs. Pediatrics 2013;132:e1664-71.

32 Erdei C, McAvoy LL, Gupta M, et al. Is zero central line-associated bloodstream infection rate sustainable? A 5-year perspective. Pediatrics 2015;135:e1485-93.

33 Shepherd EG, Kelly TJ, Vinsel JA, et al. Significant reduction of central-line associated bloodstream infections in a network of diverse neonatal nurseries. J Pediatr 2015;167:e1-3:41-6.

34 Wheeler DS, Giaccone MJ, Hutchinson N, et al. A hospital-wide quality-improvement collaborative to reduce catheter-associated bloodstream infections. Pediatrics. 2011;128(4): e995-1004; quiz e1004-7. (accessed 4th Sept 2020).

35 Semrau KEA, Hirschhorn LR, Marx Delaney M, et al. Outcomes of a coaching-based WHO safe childbirth checklist program in India. N Engl J Med 2017;377:2313-24.

36 Andersen C, Hart J, Vemgal P, et al. Neonatal Nosocomial Infection Working Group. Prospective evaluation of a multi-factorial prevention strategy on the impact of nosocomial infection in very-lowbirthweight infants. Journal of Hospital Infection 2005;61:162-7.

37 Neill S, Haithcock S, Smith PB, et al. Sustained reduction in bloodstream infections in infants at a large tertiary care neonatal intensive care unit. Adv Neonatal Care 2016;16:52. 
38 Wirtschafter DD, Pettit J, Kurtin P, et al. A statewide quality improvement collaborative to reduce neonatal central line-associated blood stream infections. J Perinatol 2010;30:170-81.

39 Payne V, Hall M, Prieto J, et al. Care bundles to reduce central line-associated bloodstream infections in the neonatal unit: a systematic review and meta-analysis. Arch Dis Child Fetal Neonatal Ed 2018;103:F422-9.

40 Aly H, Herson V, Duncan A, et al. Is bloodstream infection preventable among premature infants? A tale of two cities. Pediatrics 2005; 115:1513-8.

41 Barton L, Hodgman JE, Pavlova Z. Causes of death in the extremely low birth weight infant. Pediatrics 1999;103:446-51.
42 Murki S, Kiran S, Kumar P, et al. Quality improvement collaborative for preterm infants in healthcare facilities. Indian Pediatr 2018;55:818-23.

43 Alp E, Cookson B, Erdem H, et al. Infection control bundles in intensive care: an international cross-sectional survey in low- and middle-income countries. J Hosp Infect 2019;101:248-56.

44 Aboelela SW, Stone PW, Larson EL. Effectiveness of bundled behavioural interventions to control healthcare-associated infections: a systematic review of the literature. J Hosp Infect 2007;66:101-8.

45 Bradley J, Jayanna K, Shaw S, et al. Improving the knowledge of labour and delivery nurses in India: a randomized controlled trial of mentoring and case sheets in primary care centres. BMC Health Serv Res 2017;17:14. 